dition existing when the pulp chamber had been filled or nearly so with secondary dentine, thereby depriving the tooth of its nourishment and of that feature which we call vitality. Hence, the tooth brealss down readily. I think the answer bears on the information given us by Dr. Latham, and on the advice of those gentlemen who advise extirpation, on slight grounds, of the pulp in the apparently normal tooth. The remaining tissues of a tooth which has suffered extirpation of its pulp are placed in the condition of the senile touth. I think we should emphatically eondemn the too frequent and unnecessary extirpation of the pulp.

DR. M. J. RHEIN-What is an early age and what are normal pulps are mooted questions, and the most important question is which is the lesser evil of the two. I think all dentists recognize the evil they must do in removing pulps for certain pathologic conditions, but they are committing what they consider the lesser evil. He prefers to do that and preserve the stability of the root of the tooth, for as practical men we know that if we can preserve the integrity of the attachment of the root to the peridental tissues, as far as the crown of the tooth is concerned it matters very little. Dental art has reached such a stage that that part of the tooth can always be made presentable. I only want to press the point: Which is the lesser evil, the loss of the tooth entirely at a very early period or to preserve the roct?

Dr. Andowews (in closing) - In regard to the merging of the odontoblasts and fiber cells, the question has been much discussed. The joining or merging of cells, as the pulp grows smaller, and the newly-formed tooth closes in on it, actually takes place. I bave seen them merging together, or thought $I$ did. There are many points I would like to hear discussed, but $\Upsilon$ do not think they had better be taken up at this time.

Dr. Latham (in closing) - L am not discussing pathology. That could be better taken up twenty years hence. The point is, on what is the tooth structure based? I take the argument that it is based on the formative organ, the pulp. I am not discussing the formation of dentine, enamel or anything else. I want to get back to normal histology and I do not like such terms as myxomatous tissue. This is but beginning work. My time has been spent in collecting material. I have taken up the theories of the function of the pulp, not pathology. The pulp is a more important organ than we will allow. The nervous mechanism of the pulp is not proven. The histologic basis is not proven. Professor Paul and myself, I believe, are the only two that have made special effort to prove that there is more of a basal structure to the pulp than most investigators have allowed. I have also labored to secure the nervous mechanism, and I believe that the photograph which I showed demonstrated the raso-motor connection with the pulp. This I hope is practically put on a foundation, microscopically, clinically and photographically. The connection with the odontoblastic layer $\mathrm{I}$ am trying to prove, and have succeeded in tracing the nerve fibers to that point, but have not had time to continue the connection into the cell. The work has been carried on for about fifteen years, including the making of many modified stains, etc., and to-day it is imperfect.

Then the structure of these cells I have not taken up. I have taken up other people's theories and I have argued my paper on these, because to get back to the origin of the odontoblasts we must consider function and physiologic relations.

The connection of the pulp stones I argued on Dr. Anderson's paper, not on my own, and showed my photograph to prove her paper. $I$ mentioned that in my sections these calcareous bodies were formed all the way through. The origin of these is another thing. If they are found, how can they be formed from the odontoblasts? I rather think they can not be, unless we have the odontoblasts in this connective tissue working in a way we do not realize. I want my work to be based on general histology. I do not want the dental tissue with no other analogy in the human body, hence I have been working on the origin of the odontoblast, the blastoderm and the function of the secretory organs, but I have not proven the points. Further, I would say that a good deal of argument has been based on pathologic eonditions. This paper is simply to show you that when one speaks of the enamel organ forming he speaks of a number of layers, and not one only. The points of this and future papers is to prove the nervous relations, the struetural basis of the pulp, the varieties of the odontoblasts, which is the true odontoblast, which the formative cell, and its vasomotor and functional connection with the tooth, and then later, take up the pathologic function. This work is illustrated by carefully prepared photographs untouched, and I hope to get something that I shall call a normal pulp to make a basis for the work.

\section{PRURITUS ANI.}

STRONG HEAT I'S BEST REMEDY. NEW APPARATUS FOR ITS APPLICATION.

EDMUND ANDREWS, M.D.

EMERITUS PROFESSOR OF SURGERY IN NORTHWESTERN UNIVERSITY. CHICAGo.

Every practitioner laments the inefficiency of the treatment for pruritus ani. Only a few surgeons seem to know that very strong heat almost instantly quenches the torment of itching in any part of the body, and that the relief thus obtained generally lasts from one to several days, but the anatomic form of the anus is such that its verge, which is the principal seat of the pruritus, is situated high up between the nates or a little above the summit of a hollow cone, and so covered with folds of integument that it can hardly be reached by heat-bearing appliances. Sometimes hot douches and heated wet compresses prove effectual, but generally they do not reach the real spot whence the distress of the patient emanates. The surgeon's advice to apply heat is good in principle, but it does not enable the clumsy patient to make his applications reach the apex of the anal cone.

Before proceeding to describe the instrument designed for this work, it will be best to consider the principles involved. Pruritus, or itching, may exist in any portion of the skin or adjacent margins of mucous membranes. It is often a neuralgic affection, due only to the nervous system, but it may also arise from inflammations of the skin or the presence of toxins from pathogenic microbes, or from parasites and other external irritants. Whatever the cause and wherever the location may be the application of heat as strong as the patient can tolerate quenches the itching, and in a few moments brings relief which lasts many hours, and often many days.

In a former article I referred to a domestic practice which seems to be totally unknown to dermatologists. Northern farmers, teamsters and wood choppers are troubled in the winter with acute pernios, or chilblains on their feet. These are not usually confined, as asserted by dermatologists, to debilitated patients. They are the plague of the most vigorous and robust men. In appearance these pernios are insignificant red spots on the feet and toes. They are only slightly swollen and a little tender, but they have regular neriodical exacerbrations of pruritus. Once in 24 hours they awake into special activity and afflict the patient with violent itching, which lasts some two hours or more.

I have found existing among these men the following treatment. When the exacerbation comes on, the patient takes off his boots and stockings, throws open his stove door and holds each chilblain for a minute or two before the fire in a position where it will receive the radiant heat of red hot coals. He holds the part as near the fire as he can tolerate with the help of considerable fortitude. Having thus treated all the pernios the pruritus is completely relieved, he draws on his hose and boots and remains perfectly comfortable until the next 
day. He then repeats the process, and in three or four days is cured.

One farmer with pernios said he could not get a good effect from the dark heat radiated from the outside of his stove. He required the luminous heat emanating from red hot coals. Another patient living in the city had two patches of psoriasis, which had lasted him several years, and for which he had taken arsenic a long time in vain. In some way he discovered the benefit of heat, and relieved the pruritus by dripping a small stream of very hot water upon the patches. Occasionally he got the same relief by holding the parts above the chimney of a lighted lamp. After some months of these occasional hot applications he obtained a permanent cure.

Many other patients having pruritus from psoriasis, eczema and other causes have discovered the relief obtainable from strong heat. The emperor Napoleon I. had a life-long eczema on his thighs which caused him serious torment. His physician said he spent much time sitting in hot baths, where "he was continually reaching for the hot water faucet" to increase the temperature. I have found intelligent patients who had discovered that very hot douches relieved them of pruritus ani.

tuthors of works on rectal diseases have generally

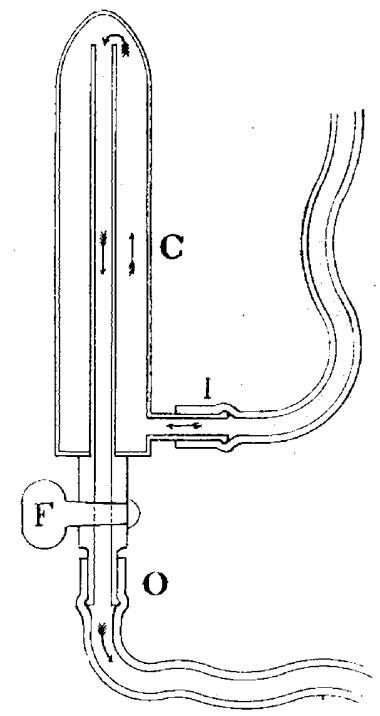

been ignorant or negligent as to this remedy, but a few of them have recognized its value and emphasized the necessity of making the heat strong. Mr. Treves, of London, says, "bathe the parts in very hot water." Dr. Joseph Mathews, of Louisville, says, "the parts should be bathed in as hot water as can be endured." Van Harlingen, of England, advised "hot water douches as hot as the skin will bear." Kelsey, of New York, directs "very hot water, and to be of any use it must be applied as hot as the finger can bear." In my own publications (Rectal and Anal Surgery) I have long advocated "hot water-as hot as can be borne."

The highest heat which is endurable is about $130 \mathrm{~F}$. Some patients will tolerate for a short time a small stream as high as $135^{\circ}$. I have never found any who could endure $140^{\circ}$. Many cannot go above $125^{\circ}$. It will be remembered that a full length hot bath cannot be used above $105^{\circ}$, but small local spots bear for a short time the higher temperatures above mentioned. To enable patients to apply sufficient heat to the anal canal without the risk of their injecting water at a dangerous temperature into the rectum itself, I have devised the instrument here shown in sectional view.
The pipes have an inside diameter of one-eighth of an inch, and the cylinder of three-quarters of an inch. The inflow pipe is simply a rubber tube leading down from a fountain syringe or other reservoir filled with water of the proper heat and hung about 4 feet above the patient's anus. Attaching the rubber tube to the nib projecting from the side of the cylinder, turn the round end of the latter upward and open the faucet $F$. The water will then expel the air and begin to run from the outflow pipe. Now close the faucet, lubricate the cylinder and insert it about two inches into the anus. Then open the faucet again and let the fluid run until the hot water begins to appear and the cylinder 'becomes as hot as the patient can properly bear. Of course, the reservoir must not be filled with water dangerously hot. It can be tested with the fingers or with a thermometer in the reservoir. In cases where tissues of the anus or of other parts are much weakened by paralysis, or by exhausting disease, I presume very high heat should not be applied.

The patient can be taught to use the instrument himself if he is reasonably intelligent. The position may be either lying on one side with the knees drawn up, or sitting obliquely on one hip, or astride a chair with the hips projecting over the edge. The treatment can be repeated from twice a day up to intervals of several days.

Of course, the surgcon will diligently examine the parts and seek to remove all discoverable causes of the pruritus, thus preventing relapses, but strong heat is the great primary remedy for the patient's sufferings. It is more than a mere temporary relief of his distress. By removing the tormenting irritation it gives the nervous tissues repose and helps to restore the parts to a healthy condition. and this principle holds true whether the pruritus be in the anus or in any other part of the bodv.

3912 Lake Arenue.

\section{ELECTRO-THERMIC HEMOSTASIS IN ABDOM- INAL AND PEIJIC SURGERY.* \\ ANDREW J. DOWNES, A.M.. M.D. \\ GYNECOLOGIST TO ST. MARY'S HOSPITAL. PHII.ADELPHIA.}

At the last meeting of the American Medical Association, in a paper with the same title as the present one, I entered into the comparative merits in hemostasis of the ligature, angiotripsy and electro-thermic pressure.

Brief reference was made to the development of electro-thermic hemostasis in the crude application by Keith of a hot iron to the compressing blades of a pédicle forceps. Credit was given Dr. Skene for devising and using instruments with a heating medium concealed and insulated within one of the compressing blades, therefore, for the introduction of electro-thermic hemostasis. I stated that the essential element in this form of hemostasis was a rapid source of heat in one blade of an instrument giving the proper amount of pressure. My own instruments were demonstrated, showing many points of improvement and practicability over Dr. Skene's. A limited number of cases with this method of hemostasis were cited. The object of the present paper is to present a greater variety of cases to prove the possibility of the common use of electro-hemostasis in place of the ligature in abdominal surgery and give its

* Read at the Fifty-third Annual Meeting of the American Medical Association. in the Section on Obstetrics and Diseases of Women, and approved for publication by the Executive Committee Drs. A. H. Cordier, W. F. B. Davis and Henry P. Newman. 